\title{
GOVERNANÇA DO PNUD EM MACEIÓ: REFLEXÕES ACERCA DAS \\ POLÍTICAS DE GESTÃo ESCOLAR PARA EDUCAÇÃO BÁSICA
}

\section{PNUD GOVERNANCE IN MACEIÓ: REFLECTIONS ON SCHOOL MANAGEMENT POLICIES FOR BASIC EDUCATION}

\author{
Sandra Regina $\mathrm{Paz}^{1}$ \\ Elainy Paula Viturino Braz ${ }^{2}$
}

\section{Resumo}

As restruturações políticas ocorridas no sistema de ensino público da capital alagoana, na última década, vêm sendo legitimadas pelas ações de organismos internacionais de tal modo que reconfigurou a gestão da educação básica a partir da governança global, tendo como mote as parcerias público-privadas. Este estudo objetiva identificar, caracterizar e analisar as principais ações desenvolvidas em parceria com o PNUD e a Secretaria de Educação; caracterizado como estudo de caso, de abordagem qualitativa, baseado na análise documental. Os resultados indicam que a governança das parcerias público-privadas têm direcionado as escolas a um "novo" modelo de gestão.

Palavras chave: Governança. Maceió. Organismos internacionais. PNUD.

\begin{abstract}
The political restructuring occurred in the public teaching system in the capital of Alagoas, in the last decade, has been legitimated by the actions of international organisms in such a way it reconfigured the management of basic education from the global governance, having the publicprivate partnerships as its motto. This study aims to identify, characterize and analyze the main actions developed in partnership with the PNUD and the Department of Education. It is characterized as a case study, within the qualitative approach, based in the documentary analysis. The findings indicate that the public-private partnerships governance has directed the schools towards a new management pattern.
\end{abstract}

Key-words: Governance. City International organisms. PNUD.

\footnotetext{
${ }^{1}$ Professora da Universidade Federal de Alagoas - UFAL. Mestre e doutora em Educação, na área de Gestão, Planejamento e Política Educacional pela UFPE. Integra o Grupo de Pesquisa Trabalho, Estado, Educação e Sociedade - GP- TESE. Pesquisa financiada pelo CNPq. E-mail: sandra.paz@cedu.ufal.br. (82) $98850-2045$.

${ }^{2}$ Graduada em Pedagogia pela Universidade Federal de Alagoas - UFAL, mestranda em Educação, na linha de pesquisa História e Política, pelo Programa de Pós-Graduação - PPGE - UFAL, foi bolsista de Iniciação Científica. Integra o Grupo de Pesquisa Trabalho, Estado, Educação e Sociedade - GP - TESE. Pesquisa financiada pelo CNPq. E-mail: elainybraz@gmail.com. (82) 99908-1552.
}

Revista de Administração Educacional, Recife, V. 1. No 2 - jul/dez. 2017 p. 04-20 


\section{INTRODUÇÃO}

As restruturações políticas ocorridas no sistema de ensino público da capital alagoana, na última década, vêm sendo legitimadas através de ações de cooperação técnica com os organismos internacionais ${ }^{3}$, de tal modo que reconfigurou a gestão da educação básica, conforme as prerrogativas da governança global, tendo como mote as parcerias público-privadas, as quais permitem múltiplos arranjos institucionais e colaborativos de parcerias entre "Estado, mercado e a sociedade civil" na prestação dos serviços educacionais públicos (NEVES, 2005, p. 96).

Tais reestruturações políticas têm corroborado na forma de gerenciamento, manifesta na forma de governança, as quais envolvem as parcerias público-privadas, cuja funcionalidade consiste em fazer o Estado atuar a partir de ações corretivas ${ }^{4}$ na prestação dos serviços educacionais. O desafio dessas ações é "regular as disfunções da educação, através de políticas educacionais que compactuem e reforcem a "dominação do capital", sob o pressuposto de promover o nivelamento das "desigualdades estruturais” ocasionadas pelas relações capitalistas (MÉSZÁROS, 2011, p. 110).

Sendo assim, as ações de parceria passam a configurar-se como uma "ferramenta" capaz de resolver os problemas socioeconômicos nas realidades locais que apresentam altas taxas de vulnerabilidade social. Consequentemente, resultando em "mudanças políticas e ideológicas”, na gestão da educação básica, para promover a égide do "desenvolvimento humano" e econômico (ROBERTSON; VERGER, 2012, p. 1140).

Neste contexto, galgam destaque as diversas ações de parcerias com organismos internacionais, dentre eles o PNUD (Programa das Nações Unidas para o

\footnotetext{
${ }^{3} \mathrm{O}$ presente artigo é um recorte da pesquisa intitulada "A "nova” governança na política educacional e a ação dos organismos internacionais: o caso de Alagoas", realizado no âmbito do PIBIC/UFAL, em conjunto com o Grupo de Estudos e Pesquisa Trabalho, Estado, Sociedade e Educação (GP-TESEUFAL/CNPq). Portanto, as pesquisas do GP-TESE têm se dedicado a investigar as ações de parcerias público-privadas no estado de Alagoas, no qual as mais expressivas são as de educação, envolvendo os organismos internacionais, com destaque para os programas: Geração Saber (parceria entre o Banco Mundial, a Secretaria Estadual de Educação e o MEC); Cidade Educar (parceria entre o PNUD, a Secretaria Municipal de Educação e o MEC); e o Viva Escola (parceria entre o PNUD, a Secretaria Municipal de Educação e o MEC).

${ }^{4}$ Segundo Meszáros (2013, p. 94), "as formações do Estado no sistema capitalista devem agir como corretivos necessários por tanto tempo enquanto forem historicamente capazes de cumprir tais ações corretivas - para alguns defeitos estruturais identificáveis na ordem do sistema sociometabólico do capital".
}

Revista de Administração Educacional, Recife, V. 1. No 2 - jul/dez. 2017 p. 04-20 
Desenvolvimento), que objetivam a promoção do desenvolvimento humano e socioeconômico sustentável, por meio de programas e projetos salvacionistas para educação básica, as quais promovem "reformas na gestão e na alocação dos recursos públicos" (BERNUSSI, 2014, p. 51).

O PNUD se estabeleceu como um dos principais mandatários no processo de gestão e restruturação do sistema público de ensino de Maceió, capital alagoana, visto que a sua função é estimular os governos municipais a adotarem uma forma de governança repleta de medidas "inovadoras" capazes de induzir a gestão educacional a "padrões básicos" de funcionamento, sob o argumento de melhorar a "qualidade" da educação básica (SILVA, 2003, p. 288). Assim, indaga-se: quais os principais aspectos e nuances das parcerias envolvendo entes públicos e privados na melhoria da gestão da educação pública no município de Maceió?

Isto posto, o presente exercício analítico objetiva identificar, caracterizar e analisar as principais ações desenvolvidas, em parceria com o PNUD e a Secretaria Municipal de Educação de Maceió, que têm como foco as restruturações políticas da gestão escolar.

Metodologicamente caracterizado como estudo de caso, de abordagem qualitativa, baseado na análise documental, a presente investigação tem como orientação o método dialético, para análise das fontes primária e secundária, cuja intencionalidade é compreender e apreender a realidade dos sujeitos e as contradições internas do objeto de estudo, pautadas na análise das políticas educacionais na área da gestão escolar (CHIZZOTI, 2006, p. 48).

Portanto, a pretensão foi fazer um recorte e apresentar a sistematização das principais expressões da governança das parcerias público-privadas que envolvem as políticas de gestão escolar no município de Maceió, implantadas pelos governos municipais em parceria com o PNUD, que se tornam um arranjo institucional que dão fundamento à governança educacional e, consequentemente, direcionam as escolas públicas um "novo” modelo de gestão na educação básica.

\section{As origens das parcerias público-privadas na gestão da educação básica}

As dinâmicas políticas e administrativas que fundamentam a governança educacional no Estado brasileiro, têm o seu ápice com as reformas da gestão pública,

Revista de Administração Educacional, Recife, V. 1. No 2 - jul/dez. 2017 p. 04-20 
implementadas na década de 1990 pelos governos de Fernando Henrique Cardoso ${ }^{5}$. Uma vez que as "novas formas de articulação entre a aparelhagem estatal e a sociedade civil" (NEVES, 2005, p. 93), inserem a "competividade e a eficiência" como características dominantes a serem viabilizadas nos "sistemas, políticas e práticas educacionais existentes" do setor público (DALE, 2010, p. 1107).

Portanto, as principais reformas empreendidas, nesta fase, estabelecem "novos" parâmetros de gerenciamento à agenda de políticas educacionais com o propósito de estreitar as relações entre os setores públicos e privados, sob o contorno da governança pública, em prol de garantir a estabilidade financeira e o desenvolvimento socioeconômico do país (ROBERTSON; VERGER, 2012). Algo que promove a "descentralização" dos sistemas de ensino públicos, por causa da "inserção de atores sociais externos", do setor privado e da sociedade civil, no gerenciamento das políticas educacionais (SANTOS; BRAGA; GUIMARÃES, 2017, p. 646).

Neste contexto, cabe destacar:

[...] o que se costuma entender por governança, nesse caso, é a substituição do pressuposto de que o Estado governa sempre e necessariamente a educação através do controle de todas as atividades de governo, pelo que se pode chamar de coordenação da coordenação, com o Estado despenhando possivelmente o papel de coordenador ou regulador de último recurso (DALE, 2010, p. 1113).

Diante disso, a gestão da educação pública, conforme os direcionamentos da governança educacional, passa a obter múltiplas coordenações, o que promove uma "expressiva mudança do papel e do formato do Estado", que encaminhadas pelas instituições do Terceiro Setor $^{6}$ ampliam o processo de privatização e terceirização na agenda de políticas educacionais (WATHIER; GUIMARÃES, 2016, p. 20).

Em outros termos, o Estado transfere a coordenação das políticas educacionais a "regulações de terceiros" como um sistema de "governo indireto", pois, se isenta de

\footnotetext{
5 Cabe ressaltar que, no Brasil, a nova governança pública se materializa por meio da Reforma Administrativa, direcionada à capacidade gerencial do Estado, que visa à a eficiência na oferta de serviços aos cidadãos. Através, do Plano Diretor de Reforma do Aparelho do Estado (BRASIL, 1995) foi orquestrado, no governo do presidente Fernando Henrique Cardoso (1995-2002), sob a gestão do ministro da administração, Luiz Carlos Bresser Pereira e, no caso da educação, mais especificamente pelo ministro Paulo Renato de Souza (SANTOS; BRAGA; GUIMARÃES, 2017, p. 647).

${ }^{6}$ Segundo Peroni (2011, p. 28), o Terceiro Setor se constitui como uma forma de quase mercado no gerenciamento das políticas públicas, no qual a sociedade civil torna-se atuante em prol da sociedade por meio de ONGs (Organizações Não Governamentais), fundações e associações civis sem fins lucrativos, organizações empresariais e Organismos Internacionais.
}

Revista de Administração Educacional, Recife, V. 1. No 2 - jul/dez. 2017 p. 04-20 
atuar como prestador dos serviços públicos, descentralizando atividades do setor público e passa a atuar apenas como regulador (MAJONE, 1999, p. 13). Desta maneira, essa "descentralização política" e de atividades se configuram de modo a perpassar os governos (DUBROW, 2013, p.102) e instituem "novas formas de governança (educacional) cada vez mais orientadas pelo mercado" (AMOS, 2010, p.33).

No entanto, o referido agrupamento de reformas administrativas no aparelho estatal, que fundamentam a governança educacional, são compartilhadas entre o Estado, as organizações empresariais e a sociedade civil (KRISSLER; HEIDEMANN, 2006, p. 482). Porém o Estado permanece como "coordenador em último recurso, o lugar para onde se dirigir quando os outros agentes de governança falham” (DALE, 2010, p. 1106) ou deixam de executar suas funções corretivas dentro do sistema capitalista.

Nesta ótica, os direcionamentos da governança educacional são intrínsecos às ações de parceiras com o Terceiro Setor, sobretudo as ações de parcerias com os Organismos Internacionais que intensificam o processo de "mundialização do capital”, e promovem a inserção de novos parâmetros internacionais pautados no desenvolvimento humano e socioeconômico sustentável (NEVES, 2005, p. 90).

As interlocuções dessas parcerias galgam destaque na coordenação dos serviços educacionais públicos por terem a funcionalidade de atender a múltiplos objetivos e interesses coetaneamente (ROBERTSON; VERGER, 2012, p. 1138), uma vez que são permissíveis a uma privatização que se "compromete" em executar o desenvolvimento com caráter mais "humanista" dentro do sistema capitalista (NEVES, 2005, p. 140).

Sendo assim, as parcerias público-privadas (PPPs) atuam na agenda das políticas educacionais como um "mecanismo promissor para minimizar os danos causados por formas anteriores de privatização, ainda que sem abandoná-las" (ROBERTSON; VERGER, 2012, p. 1139), ou seja, caracterizam-se como uma forma de privatização mais "flexível” e empreendedora dentro do sistema de ensino público.

Assim, estabelecidas no sistema de ensino, as parcerias público-privadas (PPPs) passam a empregar propostas que enfatizam a redução dos custos que envolvem os serviços públicos referentes à educação, de acordo com a lógica da "boa" governança educacional. Segundo Robertson e Verger (2012, p. 1140), a "boa governança" consiste em colocar a "eficiência" como fator determinante para os valores a serem investidos na 
educação, algo que corrobora em "práticas trabalhistas injustas, falta de transparência, resultados de má qualidade e assim por diante".

Destarte, a boa governança educacional promove a ascensão do setor privado em relação ao setor público, pois reafirma a "necessidade da privatização e da terceirização" como forma de baixar os custos dos serviços educacionais públicos (KISSLER; HEIDMANN, 2006, p.479). Por isso, o Estado deve oferecer apenas os subsídios necessários para a regulação da educação pública e viabilizar a liberalização do mercado ou a concorrência entre os setores público e privado (ROBERTSON; VERGER, 2012 p. 1144).

No entanto, a prerrogativa da boa governança ganha expressão em âmbito nacional com a permissividade do "processo de publicização" ${ }^{7 "}$ (BRASIL, 1995), das políticas de educação. As parcerias passam a compor, de forma incisiva, as atividades e as políticas que envolvem o setor educacional para melhorar a "qualidade" desses serviços, ao mesmo tempo em que "reduziam drasticamente os investimentos" na educação pública (estatal) para garantir um ambiente favorável às ações de organizações empresariais nacionais e internacionais (ARELARO, 2007, p. 913).

Desta forma, o modelo de gerenciamento da boa governança educacional das parcerias público-privadas reafirmam a flexibilização das políticas educacionais, visto que vislumbra a "educação como serviço público que pode ser transferido para as empresas privadas" (SILVA, 2003, p. 288), ou seja, como bem de consumo público, em que as parcerias substituem a privatização integral da educação pública para a promoção do desenvolvimento humano e socioeconômico.

A boa governança das parcerias público-privadas educacionais (PPPEs) atua na gestão da educação básica, como mecanismo para garantir a "equidade" entre os sujeitos, e coetaneamente auxiliar na manutenção da estabilidade econômica, pois, a legitimidade das PPPEs reside no pressuposto "de resolver alguns problemas de difícil abordagem", presentes na educação, relacionados à "temática do desenvolvimento" (ROBERTSON; VERGER, 2012, p. 1143) que se alinham tanto às problemáticas do

\footnotetext{
${ }^{7}$ Cabe ressaltar que o "Plano Diretor da Reforma do Aparelho do Estado (BRASIL, 1995) prevê, para a educação, um programa de publicização, entendendo-a como um dos serviços não exclusivos do Estado, porque não tem, necessariamente, que ser executada/prestada pelo Estado, mas regulada, facilitada, promovida ou parcialmente financiada por ele, que deixa de ser executor e passa a ser coordenador desse serviço" (COUTINHO, K., 2003, p. 958).
}

Revista de Administração Educacional, Recife, V. 1. N 2 - jul/dez. 2017 p. 04-20 
crescimento econômico quanto às problemáticas de combate à pobreza (BERNUSSI, 2014, p. 57).

Sendo assim, o setor educacional passa a estruturar-se para aderir a um projeto de educação básica com formação reducionista, que apenas atenda e ofereça “sustentação aos interesses do capital" (LEHER, 2003, p. 221), de tal modo que os programas e projetos pautados na abordagem da boa governança educacional incluem, na gestão da educação pública, novas metas de desempenho, orientadas pela eficiência, competitividade e participação do mercado. Logo, induzem as reformas políticas e administrativas que desestruturam as atividades do setor público e estimulam a presença do setor privado no campo da educação, manifestos nos programas e projetos educacionais de parcerias público-privadas (ROBERTSON; VERGER, 2012, p. 1136).

Deste modo, os programas alinhados à lógica da boa governança educacional têm quatro áreas de atuação no sistema de ensino: "financiamento; fornecimento ou oferta; propriedade; regulação" (DALE, 2010, p. 1111-1113 grifo do autor), que implementam uma cultura de gestão que "afeta tanto as políticas de financiamento, quanto outras políticas como as de currículo, formação de professores, organização da escola, práticas de avaliação etc.” (LIBÂNEO, 2012, p. 15), isto é, políticas que direcionam a gestão da educação pública à padrões mínimos de funcionamento e recursos pedagógicos.

Contudo, os programas das parcerias público-privadas atuantes no processo de gestão e restruturação da educação básica maceioense podem ser caracterizados como a "nova" privatização dentro do sistema de ensino. Embora a boa governança educacional desses programas se configure como salvacionista, suas ações têm como base garantir padrões mínimos de desenvolvimento humano e socioeconômico, de acordo com a égide política e administrativa dos Organismos Internacionais, dentre eles o PNUD. No próximo item, discutiremos os objetivos e as ações implementadas por tal organismo internacional.

\section{A GOVERNANÇA DO PNUD: considerações sobre os objetivos para a educação}

\section{básica}

Os mecanismos de gestão da boa governança educacional das parcerias públicoprivadas reafirmam a concepção das economias cada vez mais "inter-relacionadas", de 
tal modo que, direcionadas pelos "interesses do mercado", perpassam os próprios Estados e são assumidas por parcerias com organizações internacionais, como o PNUD, que estabelecem diretrizes e métodos de gerenciamento para a educação básica, conforme a agenda política de desenvolvimento sustentável (RODRIGUES, 2015, p. 3).

As diretrizes políticas e de parceria com o PNUD, atualmente, objetivam "um plano de ação para as pessoas, o planeta e a prosperidade", ou seja, uma agenda transformadora de "ações compartilhadas e de parcerias solidárias", entre as organizações empresarias, a sociedade civil e os Estados, que reconheçam as metas de erradicação da pobreza, incluindo a pobreza extrema e a fome como medidas imprescindíveis para alcançar o desenvolvimento sustentável (PNUD, 2015, p. 2).

Nesta ótica, a denominada governança sustentável do PNUD realiza a junção dos itens de desenvolvimento humano e socioeconômico, de forma reciclada e inovadora, para fomentar a construção de parcerias e políticas de combate à pobreza (MACHADO; PAMPLOMA, 2010, p. 62). Tal governança "reforça e fortalece a importância das parcerias globais em países em desenvolvimento" (PNUD, 2015, p. 31), para "garantir a dignidade e igualdade humana em todos os âmbitos", inclusive na educação (PNUD/BRASIL, 2017).

Sendo assim, a educação passa a ser vista como promotora de ações que objetivam "eliminar as disparidades sociais" e, consequentemente, galgar o desenvolvimento sustentável (PNUD/BRASIL, 2017). As metas da agenda política do PNUD ambicionam parcerias sociais transformadoras "(objetivo 4), que consiste em assegurar a educação inclusiva e equitativa de qualidade e promover oportunidades de aprendizagens ao longo da vida para todos" (PNUD, 2015, p. 19).

Em outros termos, uma boa governança educacional que responsabiliza a sociedade civil para gerenciar ações com vistas a solucionar os problemas centrais da educação (DALE, 2010, p. 1110). O principal objetivo dessas ações é promover uma educação equitativa e de "qualidade" aos sujeitos em situação de pobreza, através da "garantia de conhecimentos básicos" como o "acesso ao ensino primário e secundário (educação básica)" de maneira que possibilite a saída da pobreza e a inserção no mercado de trabalho (PNUD, 2015, p. 19).

Por conseguinte, a governança sustentável do PNUD correlaciona o acesso à educação básica ao desenvolvimento socioeconômico de tal modo que as políticas de 
parcerias viabilizadas na gestão da educação têm como base uma formação aligeirada e de caráter profissional para os sujeitos (SILVA, 2003, p. 292). Considerando que os programas de parceria com o PNUD “estabelecem parâmetros de investimentos" e diretrizes pedagógicas mínimas para educação pública (LIBÂNEO, 2012, p. 17), as quais desestruturam as ações pedagógicas e de gestão nos sistemas de ensino.

Isto posto, a boa governança educacional do PNUD é frequentemente resignificadas nas agendas políticas e nos programas de ensino com o intuito de atender as novas demandas do capital, sejam de apoiar os Estados ou de convocar a sociedade civil para melhorar a eficiência na prestação dos serviços educacionais públicos. Portanto, os novos objetivos de desenvolvimento sustentável transpõem para a gestão da educação os mesmos contornos mercantis das parcerias público-privadas educacionais, porém com o apelo à solidariedade por parte da sociedade civil.

No próximo item, discutiremos as implicações das ações de parceria com o PNUD na gestão da educação básica de Maceió. Apresentaremos os dados empíricos das ações e como estas reverberam na realidade dos sujeitos.

\section{As implicações das ações de parceria com o PNUD na gestão escolar: o caso de Maceió}

No município de Maceió, consta-se a enviesada perspectiva de que a educação se constitui como ferramenta de promoção do desenvolvimento sustentável, algo que tem se instaurado de forma contundente nas restruturações políticas e de gestão, orientadas pelos programas de parcerias com PNUD na rede municipal.

Esses programas se estabelecem sob o pressuposto de superar a ineficiência do sistema de ensino e das unidades escolares que necessitam de um novo padrão de gestão escolar, articulado à lógica da boa governança educacional, para garantir melhores desempenhos dos estudantes nos índices avaliativos nacionais.

Neste contexto, os mecanismos de gestão da educação básica municipal passaram a ser direcionados pela boa governança do PNUD, expressas nos programas e projetos na rede municipal de ensino desde o início do ano letivo de 2008, os quais se estabeleceram e foram periodicamente reciclados com o "objetivo primordial de 
"salvar" a educação dos descasos das gestões públicas realizadas em anos anteriores" (SEMED/MACEIÓ, 2016).

Desta forma, a gestão da educação básica de Maceió configura-se como flexível e empreendedora, dado que as novas diretrizes políticas dos mencionados programas redimensionam a organização e a gestão do trabalho escolar de acordo com indicações teóricas e administrativas do PNUD (VIRIATO; CÊA, 2008, p. 116), de tal modo que ampliam os controles externos e a instrumentalidade do trabalho pedagógico e escolar, em prol de obter a produtividade, a eficiência e a eficácia no sistema de ensino (ALERARO, 2007, p. 907).

Entretanto, neste momento, delimitaremos-nos a analisar as ações e diretrizes políticas direcionadas à área de gestão escolar, durante o período de 2013 a 2016, que foram estruturadas pelas parcerias entre o PNUD, o MEC (Ministério da Educação) e a SEMED/Maceió, no qual implementam o Programa Viva Escola como coluna vertebral da Rede de Ensino Municipal de Maceió - expressão da "boa governança" educacional maceioense.

Isto posto, as ações na área de gestão escolar do Programa Viva Escola têm como premissa garantir padrões básicos de funcionamento e gerenciamento para o sistema de ensino e as escolas a ele atreladas, de modo a contribuir para o alcance e a melhoria dos índices avaliativos nacionais e compor uma educação de qualidade, equitativa e inclusiva aos estudantes da rede municipal (SEMED/MACEIÓ, 2016).

Consequentemente, as ações do Viva Escola disseminam uma nova visão de neutralidade política aos eixos (planejamento, avaliação e currículo) que envolvem o trabalho da gestão escolar (VIRIATO; CÊA, 2008, p. 117). Algo que ocasiona na perda da função social e cultural da escola, numa perspectiva gramsciana ${ }^{8}$. Pois as reorganizações obtidas na área da gestão são de cunho economicista e reducionista e tem como parâmetro as transformações e necessidades do mercado, em um contexto de evolução tecnológica e econômica (ZANARDINI, 2008, p. 132).

\footnotetext{
${ }^{8}$ Segundo Gramsci, a escola tem a função social e cultural de propiciar uma formação aos estudantes de criação intelectual e de prática com autonomia, para isso, faz-se necessário à organização da "escola unitária ou de formação humanista (entendido este termo, "humanismo", em sentido amplo e não apenas em sentido tradicional) ou de cultura geral (que) deveria se propor a tarefa de inserir os jovens na atividade social, depois de tê-los levado a um certo grau de maturidade e capacidade, à criação intelectual e prática e a uma certa autonomia na orientação e na iniciativa" (GRAMSCI, 1982, p. 121).
}

Revista de Administração Educacional, Recife, V. 1. No 2 - jul/dez. 2017 p. 04-20 
Fato que nos leva a crer que as informações obtidas, referentes a ações na área de Gestão Escolar, têm por finalidade "centralizar e modernizar as informações das escolas para Secretaria Municipal, com o intuito de garantir a eficiência e a agilidade do sistema de ensino municipal” (SEMED/MACEIÓ, 2016). Propositadamente, essas ações "mercantilizam" o trabalho escolar, uma vez que impõe às escolas adequações imediatas aos "novos pacotes tecnológicos" sem oferecer os recursos necessários para o manuseio dos novos instrumentos de trabalho (LEHER, 2008, p. 223).

Nesta lógica, as ações realizadas, no ano letivo de 2015 e no início de 2016, concentram-se na aquisição e implementação na rede municipal da plataforma de informações QEdu ${ }^{9}$, nomeada no município de SisLame, e das matrículas Online. Na qual foram noticiadas pouquíssimas capacitações de servidores e servidoras, tanto da SEMED quanto das escolas, assim, constatando a inclusão de estagiários e técnicos do PNUD como responsáveis por supervisionar e garantir a manutenção e, em muitos casos, o manuseio dos novos recursos tecnológicos de trabalho (SEMED/MACEIÓ, 2016).

Portanto, existem controvérsias acerca da eficiência e da agilidade das ações que visavam a modernização, pois obtiveram mudanças irrisórias na qualidade da gestão da educação básica municipal. Visto que essas restruturações, apesar de "conectarem" o sistema de ensino com as escolas, preconizam e reafirmam o modelo de gestão "vertical" e "autoritário", viabilizado pela SEMED/Maceió (SILVA, 2003 p. 284), cuja funcionalidade dessas ações é a de centralizar as informações das escolas, consequentemente, retirar a autonomia dos servidores e das direções das unidades escolares.

Sendo assim, nas mencionadas restruturações, a centralização de poder se trasveste em atividades ditas eficientes, pois os limites e as necessidades de manutenção das ações executadas são previamente determinados (VIRIATO; CÊA, 2008, p. 117). Porém os recursos tecnológicos são medidas necessárias para a flexibilização da governança educacional (ZANARDINI, 2008, p.138), obviamente que, nesse caso, com formas organizacionais ineficientes e burocráticas.

\footnotetext{
${ }^{9}$ A plataforma QEdu tem por objetivo auxiliar os gestores, diretores e professores a fazerem melhores escolhas referentes à educação brasileira. Assim, inovando no uso das tecnologias para centralizar informações sobre o censo escolar, índices de avaliação, dentre outros, para suprir os dados educacionais que fazem a diferença na gestão escolar e criam uma rede de pessoas engajadas em transformar a educação básica brasileira (FUNDAÇÃO LEMANN).
}

Revista de Administração Educacional, Recife, V. 1. No 2 - jul/dez. 2017 p. 04-20 
Ainda, no segundo semestre do ano letivo de 2016, a ação mais divulgada na área de gestão escolar, do Programa Viva Escola, foi o Guia Prático de Gestão Escolar da Rede Municipal de Ensino de Maceió: orientações para formação continuada de gestores escolares (SEMED/Maceió, 2016). Esse documento pode ser considerado o produto mais expressivo das diretrizes políticas e gerenciais do Viva Escola, pois objetiva atuar como ação corretiva de todas as outras ações na área de gestão escolar, inclusive na formação dos gestores escolares, devido ao fato de padronizar e inserir as perspectivas políticas do PNUD na gestão do sistema de ensino.

Deste modo, o Guia Prático de Gestão tem a pretensão de nortear as ações dos gestores e da comunidade escolar, no que concerne ao "novo" modelo de organização da gestão, de modo que estabelece metas de parcerias para garantir um trabalho de qualidade na obtenção dos índices de "desenvolvimento sustentável”, cujo intuito é "assegurar uma educação inclusiva e equitativa" a todos (SEMED, 2016, p. 19). Uma vez que o modelo de gestão viabilizado pelo Programa Viva Escola transfere para a gestão escolar o papel de "apenas reproduzir metas e planos" (SILVA, 2003, p. 298) elaborados por técnicos do PNUD, que geralmente desconhecem a realidade do município e dos sujeitos.

Nessa linha de raciocínio, a SEMED passa a fomentar ações que "agreguem parceiros para as instituições escolares com a finalidade de aumentar os mecanismos de governança da gestão escolar” (SEMED, 2016, p. 17), ou seja, o Guia Prático de Gestão expressa um modelo de "gerenciamento neoliberal" que incentiva, no âmbito das escolas, a realização de "parcerias público-privadas de diversas ordens", como sinônimo de boa governança educacional (ROBERTSON, 2012 p. 285).

Em outros termos, a escola deve promover "parcerias solidárias" que auxiliem na resolução dos problemas que envolvem a gestão escolar, tais como: estruturais, pedagógicos, de financiamento, dentre outros, de tal modo que a gestão escolar se responsabilize de instituir parcerias com a "sociedade civil organizada", a fim de promover uma educação de "qualidade" para a comunidade local (NEVES, 2005, p. 97).

Deste modo, a "nova ordem" política e de gestão escolar, vista em cartilhas de "métodos replicáveis", proposta pelo PNUD, em Maceió, quando executada, desencadeia uma gestão gerencial, na qual são instrumentalizados os gestores e a

Revista de Administração Educacional, Recife, V. 1. No 2 - jul/dez. 2017 p. 04-20 
comunidade escolar para serem atuantes na busca de uma educação equitativa e de aparente qualidade (PERONI, 2012, p. 29).

Segundo Viriato e Cêa (2008, p. 113), a gestão gerencial caracteriza-se por uma herança de organização no trabalho escolar, o que implica em alterações no trabalho dos profissionais envolvidos com a gestão escolar. Uma vez que,

[...] delineia-se em uma forma de organização e gestão que busque, nos próprios sujeitos sociais inerentes ao processo educacional (professores, equipe pedagógica, pais, alunos e comunidade) propostas e ações autônomas para executar políticas educacionais emanadas do Estado com eficiência, eficácia, agilidade e resultado, compartilhando assim responsabilidades que até então eram eminentemente estatais (VIRIATO; CÊA, 2008, p. 114).

Portanto, o mencionado modelo de gestão viabiliza "ações neoliberais", que articulam "novas formas de privatização", para manutenção das escolas durante todo o ano letivo (ROBERTSON, 2012, p. 292), sejam elas de responsabilidade da comunidade local e escolar ou das parcerias público-privadas, contanto que promovam as "ações voluntárias" ou parcerias solidárias, que minimizem os danos causados pela ausência de ações e recursos públicos advindos do Estado (NEVES, 2005, p. 101).

Neste sentido, o Guia Prático de Gestão expressa que a governança induzida pelo PNUD reafirma a dependência técnica e política da SEMED no gerenciamento da gestão educacional, tendo em vista que o mencionado documento de política apresenta metas e ações que corroboram na perspectiva da boa governança educacional no município, pois responsabilizam a escola pelas ações de gestão e melhorias no sistema de ensino, assim, compondo uma forma de "gestão política minimalista" (SILVA, 2003).

A boa governança, induzida pelo Programa Viva Escola, delineou-se como pouco eficaz em relação à proposta inicial de melhorar a qualidade do ensino da rede municipal (SEMED/MACEIÓ, 2016), uma vez que as ações realizadas na área de gestão escolar obtiveram resultados pouco efetivos, por motivos de diversas ordens, tais como: restruturações políticas destoantes da realidade educacional; responsabilização dos gestores e da comunidade em promover melhorias que não lhes são atribuições; instrumentalizar o trabalho pedagógico; burocratizar ainda mais o trabalho escolar, dentre outros.

Revista de Administração Educacional, Recife, V. 1. No 2 - jul/dez. 2017 p. 04-20 
Contudo, a boa governança educacional viabilizada por organizações como o PNUD, reafirma a composição de uma gestão da educação generalista que possui resultados poucos expressivos na realidade educacional, mas que possibilita o discurso hegemônico e o apaziguamento social de algo que está sendo realizado para melhorar a qualidade da educação pública.

O mencionado "apaziguamento social" caracteriza-se pela hegemonia presente nos direcionamentos políticos da gestão escolar que, gradativamente, inserem a instrumentalização do trabalho pedagógico e escolar, no qual a neutralidade política da boa governança educacional ocasiona em supostas melhorias no sistema de ensino (NEVES, 2005).

Para alcançar a tão almejada "boa governança" no município de Maceió, este precisa, ainda, superar a concepção instrumental de que os sujeitos sozinhos são responsáveis pelas melhorias na educação, através da utilização de guias instrumentais de gestão, assim como resgatar a sua autonomia política e didático-pedagógica como ente público frente às determinações de organismos externos à educação pública.

\section{REFERÊNCIAS}

AMOS, Karin. Governança e governamentalidade: relação e relevância de dois conceitos científico-sociais proeminentes na educação comparada. Educação e Pesquisa, São Paulo, v. 36, n. especial, p. 23-38, abr., 2010.

ARELARO, Lisete R. G. Formulação e implementação das políticas públicas em educação e as parcerias público-privadas: impasse democrático ou mistificação política? Educ. Soc. Campinas, v. 28, n. 100, p. 899-919, out., 2007.

BERNUSSI, Mariana Medeiros. Instituições internacionais e educação: a agenda do Banco Mundial e do educcation for all no caso brasileiro. 2014. 101 f. Dissertação (Mestrado em Educação) - Universidade de São Paulo, São Paulo, 2014.

BRASIL. Plano Diretor da Reforma do Aparelho do Estado. Brasília: Presidência da República, Câmara da Reforma do Estado. Ministério da Administração Federal e Reforma do Estado, 1995.

CHIZOTTI, Antonio. Pesquisa qualitativa em ciências humanas e sociais. Petrópolis: Vozes, 2006.

COUTINHO, Karyne Dias. Educação como mercadoria: o público e o privado no caso dos Shopping Centers. Educ. Soc., Campinas, v. 24, n. 84, p. 955- 982, set., 2003. 
DALE, Roger. A sociologia da educação e o Estado após a globalização. Educ. Soc., Campinas, v. 31, n. 113, p. 1099 -1120, out./dez., 2010.

DUBROW, Joshua Kjerulf. Governança Global Democrática, Desigualdade Política e a Hipótese da Resistência Nacionalista. Sociologias, Porto Alegre, n. 32, p. 94-110, jan./abr., 2013.

GRAMSCI, Antonio. Os Intelectuais e a Organização da Cultura. 4. ed. Rio de Janeiro: Civilização Brasileira, 1982.

KISSLER, Leo; HEIDEMANN, Francisco G. Governança pública: novo modelo regulatório para as relações entre Estado, mercado e sociedade? RAP, Rio de Janeiro, $\mathrm{n}$. 40, p. 479-499, maio/jun., 2006.

LEHER, Roberto. Reforma do Estado: o privado contra o público. Trabalho, Educação e Saúde, Rio de Janeiro, v. 1, n. 2, p. 203-228, set., 2003.

LIBÂNEO, José Carlos. O dualismo perverso da escola pública brasileira: escola do conhecimento para os ricos, escola do acolhimento social para os pobres. Rev.

Educação e Pesquisa, São Paulo, v. 38, n. 1, p. 13-28, jan./mar., 2012.

MACEIÓ. Secretaria Municipal de Educação. Guia Prático de Gestão Escolar da Rede Municipal de Ensino de Maceió: orientações para formação continuada de gestores escolares. Maceió: Viva, 2016.

MACHADO, João G. Rocha; PAMPLONA, João Batista. Caracterização e avaliação do desempenho do PNUD no Brasil segundo sua estratégia e forma de atuação.

PESQUISA \& DEBATE, São Paulo, vol. 21, n. 1, p. 157-184, 2010.

MAJONE, Giandomenico. Do Estado positivo ao Estado regulador: causas e consequências de mudanças no modo de governança. Rev. do Serviço Público, v. 50, n. 1, p. 5-36, jan./mar., 1999.

MÉSZÁROS, István. A montanha que devemos conquistar. São Paulo: Boitempo, 2015. 2011 .

Para além do capital: rumo a uma teoria da transição. São Paulo: Boitempo,

NEVES, Lúcia Maria Wanderley. A sociedade civil como espaço estratégico de difusão da nova pedagogia de hegemonia. In: NEVES, L. M. W. (Org.). A nova Pedagogia da Hegemonia: estratégias do capital para educar o consenso. São Paulo: Xamã, 2005. p. 85-127.

PERONI, Vera Maria Vidal. A gestão democrática da educação em tempos de parceria entre o público e o privado. Rev. Pro-Posições, Campinas, v. 23, n. 2, ano 68, p. 19-31, maio/ago., 2012. 
PERONI, Vera Maria Vidal. Mudanças no papel do Estado e políticas públicas de educação: notas sobre a relação público/privado. In: PERONI, V. M.V.; ROSSI, A. L. (Org.). Políticas educacionais em tempos de redefinições no papel do Estado: implicações para a democratização da educação. Porto Alegre: Ed. Universitária da UFPEL, 2011. p. 23-42

PROGRAMA DAS NAÇÕES UNIDAS PARA O DESENVOLVIMENTO - PNUD. Transformando o nosso mundo: Agenda de 2030 para o desenvolvimento sustentável. UNIC- RIO, ed. PNUD, 2015.

PROGRAMA DAS NAÇÕES UNIDAS PARA O DESENVOLVIMENTO. PNUDBRASIL. Sobre o Brasil. Disponível em: <http://www.br.undp.org/>. Acesso em: 10 abr. 2017.

ROBERTSON, Susan L. A estranha não morte da privatização neoliberal na estratégia 2020 para educação no Banco Mundial. Rev. Brasileira de educação, Bristol, v.17, n. 50, p. 283-302, maio/ago., 2012.

ROBERTSON, Susan; VERGER, Antoni. A origem das parcerias público-privada na governança global da educação. Rev. Educ., Campinas, Soc., v. 33, n. 121, p. 11331156, out./dez., 2012.

RODRIGUES, Carlos Eduardo Serrina de Lima. Habilidades socioemocionais: a OCDE e seu projeto de governança educacional global. In: $3^{\mathbf{a}}$ Reunião Nacional da ANPEd, UFSC, Florianópolis, out. 2015.

SANTOS, Aline Veiga; BRAGA, Isabela C. Marins; GUIMARÃES, Ranilce M. Iosif A governança no contexto da pesquisa em educação no Brasil. Linhas Críticas, Brasília, v. 22, n.49, p.642-666, jan., 2017.

SECRETARIA MUNICIPAL DE EDUCAÇÃO. SEMED-AL. Programa Viva Escola. Disponível em: <http://www.maceio.al.gov.br/semed/noticias/educacao-prefeiturafirma-parceria-com-nacoes-unidas/>. Acesso em: 10 jul. 2016.

SILVA, Maria Abádia da. Do projeto político do banco mundial ao projeto político pedagógico da escola pública brasileira. Cad. Cedes, Campinas, v. 23, n. 61, p. 283301, dez., 2003.

VIRIATO, Edaquimar; CÊA, Georgia. Implicações da perspectiva gerencial aplicada à organização e à gestão escolar. In: FIGUEIREDO, I. M. Z.; ZANARDINI, I.M. S.; DEITOS, R.A. (orgs.) Educação, políticas sociais e Estado no Brasil. Curitiba: EDUNIOESTE/Fundação Araucária, 2008. p. 105-129.

WATHIER, Valdoir Pedro; GUIMARÃES, Ranilce Iosif. As múltiplas faces da governança no financiamento da educação: relações entre TCU e OCDE. Rev. FINEDUCA, Porto Alegre, v.6, n.2, p. 18-32, 2016

ZANARDINI, Isaura Mônica Souza. Reforma do Estado e da Gestão Escolar: uma leitura da articulação via a eficiência gerencial. In: FIGUEIREDO, I. M. Z.;

Revista de Administração Educacional, Recife, V. 1. N 2 - jul/dez. 2017 p. 04-20 
ZANARDINI, I.M. S.; DEITOS, R.A. (Orgs.) Educação, políticas sociais e Estado no Brasil. Curitiba: EDUNIOESTE/Fundação Araucária, 2008. p. 131-154. 